\title{
Effect of increased manganese addition and mould type on the slurry erosion characteristics of $\mathrm{Cr}-\mathrm{Mn}$ iron systems
}

\author{
P SAMPATHKUMARAN*, C RANGANATHAIAH ${ }^{\dagger}$, S SEETHARAMU and KISHORE ${ }^{\dagger \dagger}$ \\ Materials Technology Division, Central Power Research Institute, Bangalore 560 080, India \\ ${ }^{\dagger}$ Department of Studies in Physics, University of Mysore, Mysore 570 005, India \\ ${ }^{\dagger \dagger}$ Department of Materials Engineering, Indian Institute of Science, Bangalore 560 012, India
}

MS received 16 April 2008

\begin{abstract}
The wear resistance of high chromium iron is well recorded. However, the same is not the case as regards the use of manganese at higher percentages in high chromium irons and its influence on wear behaviour. Hence, this work highlights the slurry wear characteristics of chromium ( $\square$ 16-19\%) iron following the introduction of manganese at two levels i.e. 5 and $10 \%$. It is known that the wear properties are dictated by the microstructural features. To alter the structure, the cooling rate of casting has been varied by adopting two different types of moulds (i.e. sand and metal) and subsequently subjecting to thermal treatment. The as-cast and heat treated samples are examined for microstructure and then evaluated for hardness and slurry erosion properties. As the manganese content is increased from 5 to $10 \%$, the hardness showed a decrease in value both in the as-cast and heat treated conditions. The slurry erosion loss, expectedly, showed an increase irrespective of the sample condition (i.e. mould type/heat treatment adopted). The findings are corroborated with the microstructural features obtained through optical and scanning electron microscopy.
\end{abstract}

Keywords. Chromium-manganese iron; As-cast; metal and sand moulds; heat-treated; slurry erosion; optical and scanning electron microscopy.

\section{Introduction}

Thermal power stations in India encounter metal wastage on account of wear in certain critical parts such as coal and ash handling equipments, pressure parts etc (Hebbar and Seshan 1989; Seetharamu and Sampathkumaran 1991). The reason for this is attributed to the high percentage of alpha quartz present in the coal. The materials used to combat such wear out, are generally ferrous based. Among them, high chromium irons have good potential to serve abrasive situations in view of the fact that they contain hard carbides $\left(\mathrm{M}_{7} \mathrm{C}_{3}\right)$ (Gundlach and Doane 1997; Oh et al 2007) in a martensitic matrix (Gundlach 1988). While some reports are available (Maratray 1981; Sapate and Rama Rao 2006) in respect of some aspects of wear behaviour of high chromium irons under dry conditions, only limited efforts have been made by researchers to study the slurry erosion property of such irons having the gamma phase stabilizing elements (Patwardhan et al 1981; Nong et al 2005; Tekeli et al 2007) viz. nickel (Ni) and manganese $(\mathrm{Mn})$ etc. Here again, information on the use of manganese to chromium $(\mathrm{Cr}$ ) iron beyond $5 \%$ (Basak et al 1981; Sampathkumaran et al 2005) is limited. Hence, the present work focuses on developing and characterizing

*Author for correspondence (sampath@powersearch.cpri.res.in) high $\mathrm{Cr}(\sim 16-19 \%)$ iron with $\mathrm{Mn}$ additions at two ( $\sim 5$ and $10 \%$ ) levels for slurry wear properties both in the ascast and heat treated conditions. The samples made in sand and metal moulds were used for the study. The approach includes incorporation of the structure property relationship, established through optical and scanning electron microscopic studies, into the report.

\section{Experimental}

In the experimental work, $\mathrm{Cr}-\mathrm{Mn}$ iron castings were made by induction melting and casting route. The samples made from the castings were subjected to heat treatment. The samples were then characterized for hardness and slurry erosion properties followed by the microstructural examination involving optical and scanning microscopy as detailed below.

\subsection{Material preparation}

The charge materials such as ferromanganese, ferrochrome, mild steel scrap were added sequentially to produce castings of size $125 \times 150 \times 25 \mathrm{~mm}^{3}$, both in sand and grey iron moulds, by the induction melting and casting process. An earlier report (Sampathkumaran et al 2005) contains details on melting and casting procedures followed. 


\subsection{Heat treatment}

Heat treatment involving austenitization soak at $960^{\circ} \mathrm{C}$ for $2 \mathrm{~h}$ followed by oil quench were given to the test samples of size $75 \times 25 \times 6 \mathrm{~mm}^{3}$, made from the castings. Subsequently, the samples were tempered at $200^{\circ} \mathrm{C}$ for $30 \mathrm{~min}$, followed by air cooling to room temperature.

\subsection{Slurry erosion property}

The schematic diagram of the test set up is shown in figure 1. Four numbers of test samples of size $75 \times 25 \times 6 \mathrm{~mm}^{3}$ were weighed in a high precision digital electronic balance. Following this, they were kept in the sample holder, attached to a disc, by lifting the disc assembly through a rotary arrangement. A motor through a belt, connected between two pulleys, drives the disc assembly consisting of a disc and a shaft. A double-walled slurry tank, made of steel, was filled with AFS 60 grade silica sand and water in $1: 1$ proportion by weight. The water tank was provided with an inlet and outlet connections for the continuous flow of water from a tap to cool the inside portion of the tank. The test was started after closing the lid and positioning one side of the belt in one of the two slots provided on the motor side to get $500 \mathrm{rpm}$ and the other side was connected to the other pulley attached to the disc assembly. Four baffle plates were provided inside the slurry tank for effective churning action of the slurry media. The test was stopped at the end of two hours. The samples were then removed, cleaned and again weighed. The difference in the value between the initial and final weights, indicating the slurry erosion weight loss, was used in the data analysis. Three measurements were done on two representative samples (i.e. leading to a total of six readings) and the average value calculated thus was used for data reporting. The repeatability of test wear runs was ascertained by determining the coefficient of variation (CV) (Annual Book of ASTM Standards 1984).

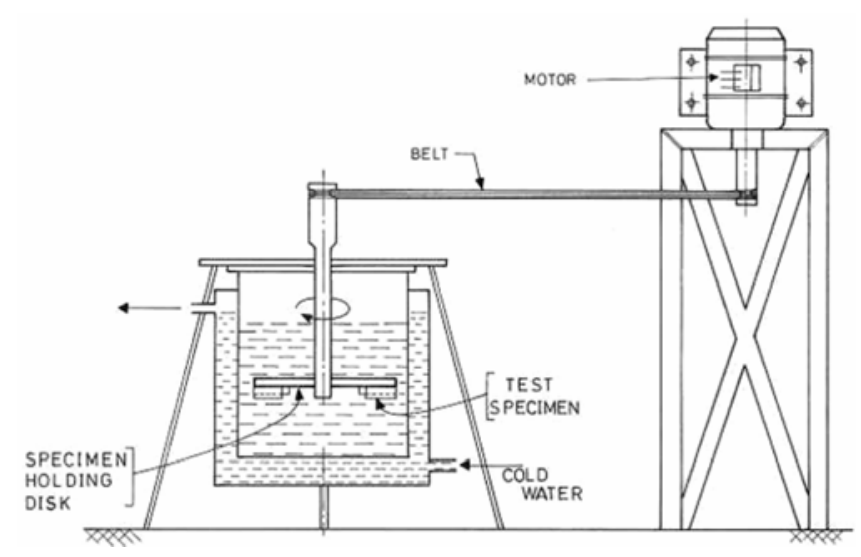

Figure 1. Schematic diagram of slurry erosion test set up.

\subsection{Hardness}

INSTRON WOLPERT machine was used to measure the hardness on Rockwell ' $C$ ' scale (HRc) using a diamond cone type of indentor, at a load of $150 \mathrm{kgf}$. Average of six readings, three each taken on two representative samples, was calculated and reported.

\subsection{Microstructure}

NIKON optical metallurgical microscope was used to study the microstructural features. An image analyzer was employed to determine the carbide volume fraction in the samples. XRD technique was adopted to measure the retained austenite content using RIGAKU X-ray analyser. The finer surface features, on select samples, were examined using LEICA scanning electron microscope (SEM).

\section{Results and discussion}

The chemical compositions of the castings are given in table 1. As regards the sample designations, the codes used have first a numeral followed by a letter and then the number 24 (representing the cast section size in $\mathrm{mm}$ ). Hence, $5 \% \mathrm{Mn}$ bearing metal cast sample of $24 \mathrm{~mm} \mathrm{sec}-$ tion thickness is designated as $5 \mathrm{M} 24$, while the $10 \% \mathrm{Mn}$ bearing sand moulded sample has the symbol 10S24. In all the bar charts and table 2, the abbreviations AC and HT stand for as-cast and heat treated conditions, respectively. The slurry erosion data of 5M24 and 10M24 are shown in figure 2 . Figure 3 shows the same data for the sand cast counterparts viz. 5S24 and 10S24. The hardness, carbide volume (CV) and retained austenite (RA) content are listed in table 2. The optical microscopic features of 5M24, 5S24 and 10S24 cases are displayed in figures 4,5 and 6 , respectively. In figures 2 and 3, the slurry erosion data in the form of bar diagrams for 5M24 and 10M24, following heat treatment (HT), are also displayed. Figures 7 and 8, respectively display the optical microscopic features of 5M24 and 10M24 following heat treatment. Similarly, figures 9 and 10 show the features of heat treated 5S24 and 10S24, respectively. The SEM features of heat treated $5 \mathrm{M} 24$ and $10 \mathrm{M} 24$ samples are displayed in figures 11 and 12, respectively.

\subsection{Effect of mould variety on slurry erosion properties}

From figures 2 and 3, it is observed that the slurry erosion loss of 10M24 as-cast samples is higher compared to $5 \mathrm{M} 24$ case irrespective of the mould type deployed. The data in figures 2 and 3 are on the expected lines in view of the fact that 5M24 shows higher hardness $(55 \mathrm{HRc}$, table 2) and desirable microstructural features compared to 
Table 1. Chemical composition of chromium manganese iron samples

\begin{tabular}{|c|c|c|c|c|c|c|c|c|}
\hline \multirow{2}{*}{$\begin{array}{l}\text { Sl. } \\
\text { no. }\end{array}$} & \multirow[b]{2}{*}{ Sample designation } & \multicolumn{6}{|c|}{ Composition (wt. \%) } & \multirow[b]{2}{*}{$\mathrm{P}$} \\
\hline & & $\mathrm{C}$ & $\mathrm{Mn}$ & $\mathrm{Cr}$ & $\mathrm{Ni}$ & Mo & $\mathrm{S}$ & \\
\hline 1 & $5 \mathrm{M} 24$ & $2 \cdot 55$ & $4 \cdot 6$ & $18 \cdot 4$ & $0 \cdot 95$ & $1 \cdot 70$ & $0 \cdot 090$ & $0 \cdot 044$ \\
\hline 2 & $5 \mathrm{~S} 24$ & $2 \cdot 95$ & $4 \cdot 5$ & $18 \cdot 0$ & $1 \cdot 10$ & 1.70 & 0.062 & 0.037 \\
\hline 3 & 10M24 & 2.75 & $9 \cdot 6$ & $16 \cdot 7$ & $0 \cdot 90$ & 1.65 & 0.085 & $0 \cdot 040$ \\
\hline 4 & $10 \mathrm{~S} 24$ & $2 \cdot 70$ & $9 \cdot 5$ & $16 \cdot 1$ & $1 \cdot 00$ & 1.90 & $0 \cdot 090$ & 0.030 \\
\hline
\end{tabular}

Table 2. Hardness, retained austenite (RA) (\%) and carbide volume (CV) (\%) recorded for the samples.

\begin{tabular}{|c|c|c|c|c|c|c|}
\hline \multirow{3}{*}{$\begin{array}{l}\text { S1. } \\
\text { no. }\end{array}$} & \multirow[b]{3}{*}{ Sample designation } & & & \multicolumn{3}{|c|}{ Microstructural content } \\
\hline & & \multicolumn{2}{|c|}{ Hardness (HRc) } & \multicolumn{2}{|c|}{ Range in RA (\%) } & \multirow{2}{*}{$\begin{array}{c}\text { Range } \\
\text { in CV } \\
(\%)\end{array}$} \\
\hline & & $\mathrm{AC}$ & HT & $\mathrm{AC}$ & HT & \\
\hline 1 & $5 \mathrm{M} 24$ & 55 & 61 & $56-58$ & $49-51$ & $26-29$ \\
\hline 2 & $5 \mathrm{~S} 24$ & 48 & 52 & $65-67$ & $61-63$ & $28-31$ \\
\hline 3 & $10 \mathrm{M} 24$ & 50 & 53 & $61-65$ & $59-61$ & $24-27$ \\
\hline 4 & $10 \mathrm{~S} 24$ & 47 & 51 & $67-70$ & $66-68$ & $23-26$ \\
\hline
\end{tabular}

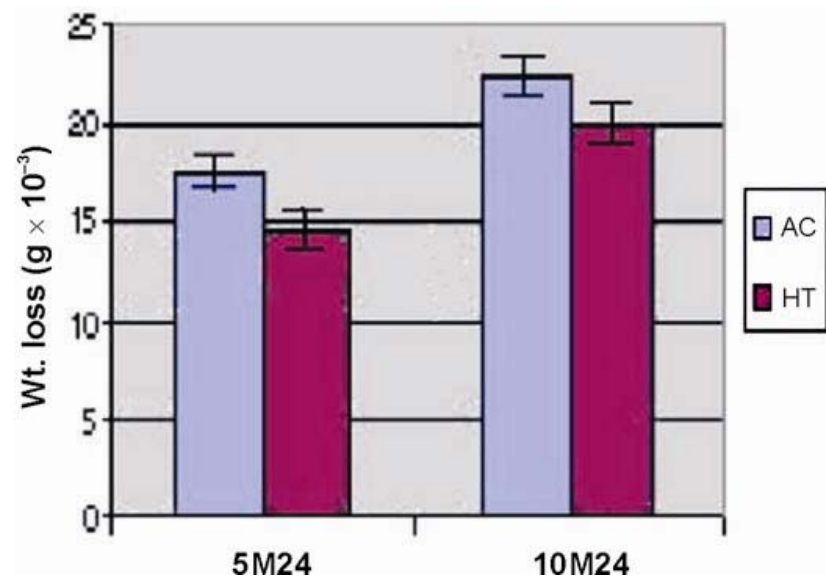

Figure 2. Bar chart showing the slurry erosion weight loss of 5M24 and 10M24 metal cooled AC and HT samples.

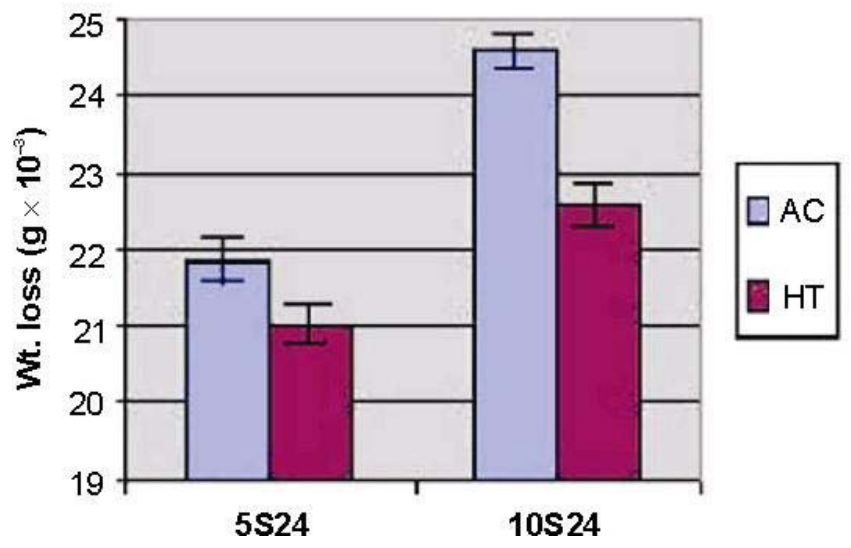

Figure 3. Bar chart showing the slurry erosion weight loss of $5 \mathrm{~S} 24$ and 10S24 sand mould cooled AC and HT samples.

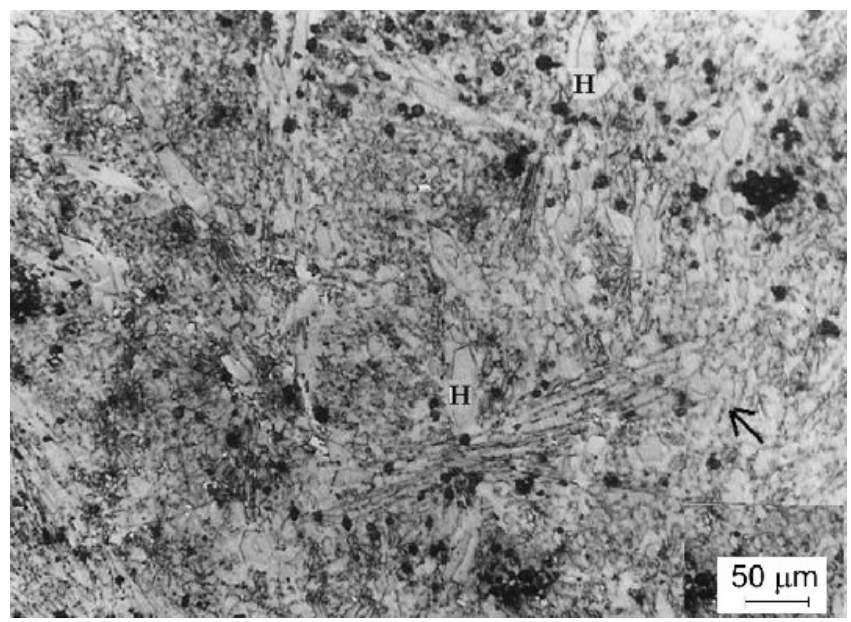

Figure 4. Optical photomicrograph of AC metal mould 5\% manganese bearing sample (200X).

$10 \mathrm{M} 24(50 \mathrm{HRc}) .5 \mathrm{M} 24$ shows (figure 4$)$ the presence of small-sized primary carbides with occasional hexagonal carbides (marked ' $\mathrm{H}$ ') in an austenitic (57\%, marked by arrow) matrix. On the other hand, medium-sized primary carbides of higher aspect ratio in a higher austenitic (63\%) matrix are observed in 10M24. Thus, microstructurally, $5 \mathrm{M} 24$ shows presence of carbides of smaller size, higher carbide volume and lower austenite content (refer figures 4, 5 and table 2) compared to $10 \%$ manganese case, all of which pointing to lower slurry erosion loss.

The sample, 5S24, exhibits (figure 5) randomly distributed medium-sized carbides structure. In addition to this, massive carbides (marked ' $M$ ') are also noticed in an austenitic (66\%) matrix (marked by arrow). 10S24 (figure 
6), on the other hand, shows carbides of higher aspect ratio compared to 5S24 (figure 5) with retained austenite of $69 \%$. The hardness of 5S24 and 10S24 are 48 and $47 \mathrm{HRc}$, respectively (table 2 ). It is seen from figure 3 that slurry erosion loss in the as-cast condition is higher in 10S24 compared to $5 \mathrm{~S} 24$ like in the metal mould case. The reason for such a trend is attributed to the carbides in 10S24 being bigger in size with higher austenite retention and the attendant lower hardness compared to $5 \mathrm{~S} 24$.

The effect of thermal treatment on the slurry erosion properties are also displayed in figures 2 and 3. In both the moulds, it is seen that an increase in manganese content results in increase in slurry erosion losses. These trends can be explained based on the microstructural features. 5M24 (figure 7) shows the presence of small-sized primary carbides plus hexagonal carbides (marked ' $\mathrm{C}$ '). On the other hand, 10M24 (figure 8) shows medium and higher aspect ratio carbides (marked 'L'). The sand

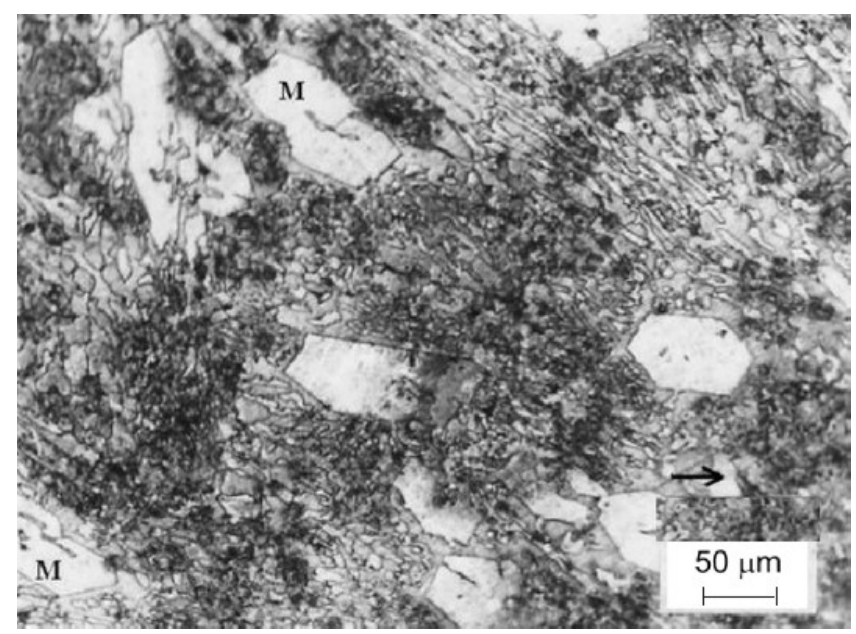

Figure 5. Optical photomicrograph of AC sand mould 5\% manganese bearing sample (200X).

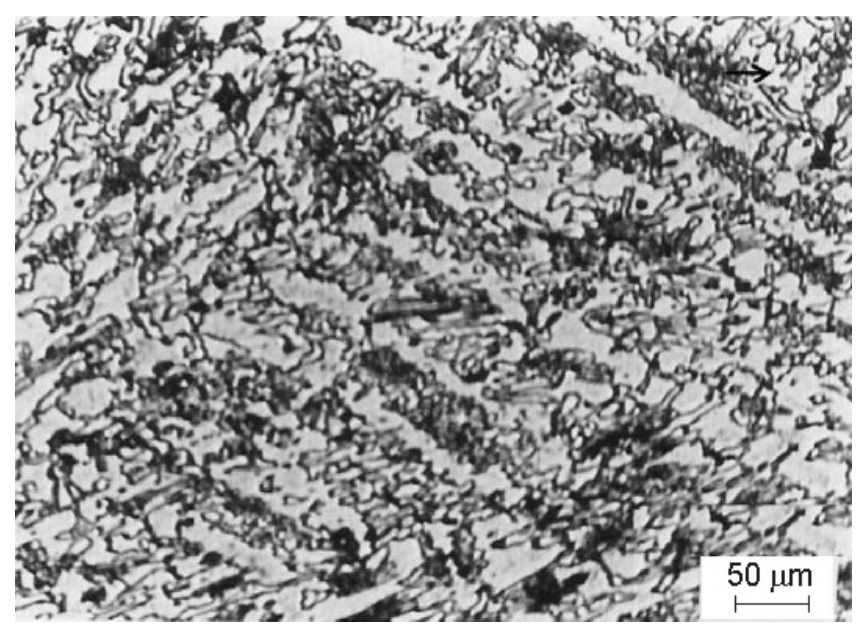

Figure 6. Optical photomicrograph of AC sand mould 10\% manganese bearing sample (200X). moulded 5\% manganese bearing sample (figure 9) shows randomly distributed carbides plus big carbides (marked ' $B$ '). The lenticular types of carbides (marked ' $S$ ') are seen in 10S24 (figure 10). Retained austenite has increased with increase in manganese content in both the cases of mould variety adopted. The occurrence of spheroidization of carbides, following heat treatment in the metal (5M24) mould case, is seen in the SEM photograph displayed in figure 11. Figure 12 shows the SEM picture of the sand moulded counterpart (5S24), wherein randomly distributed carbides (earlier recorded through optical microscope, figure 9) are seen. The feature of spheroidization of carbides seen in 5M24 due to the heat treatment could be a prime factor contributing to lower slurry erosion loss compared to 10M24. Thus, the SEM features reinforce the findings of optical micrographic features which were used to explain the lower slurry erosion loss in 5M24

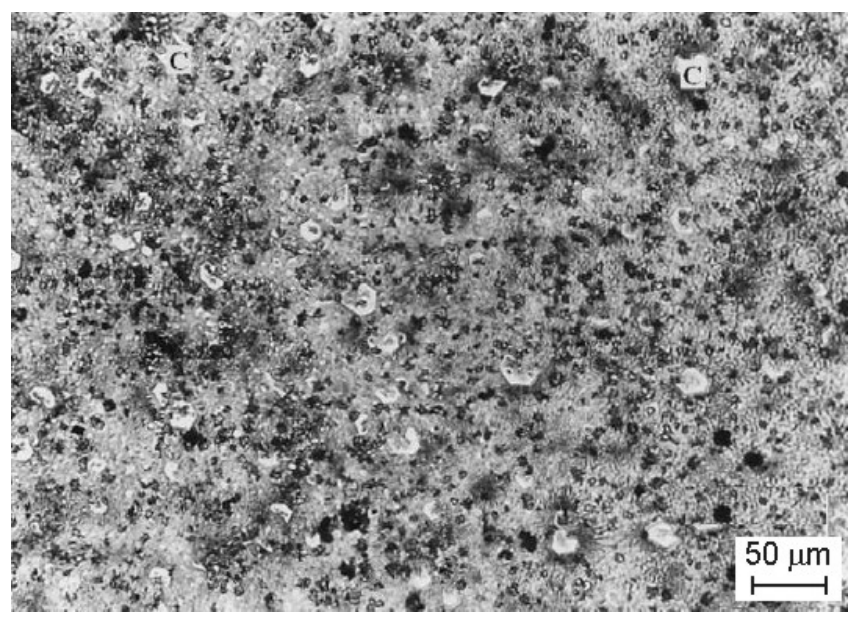

Figure 7. Optical photomicrograph of HT metal cast 5\% manganese bearing sample (200X).

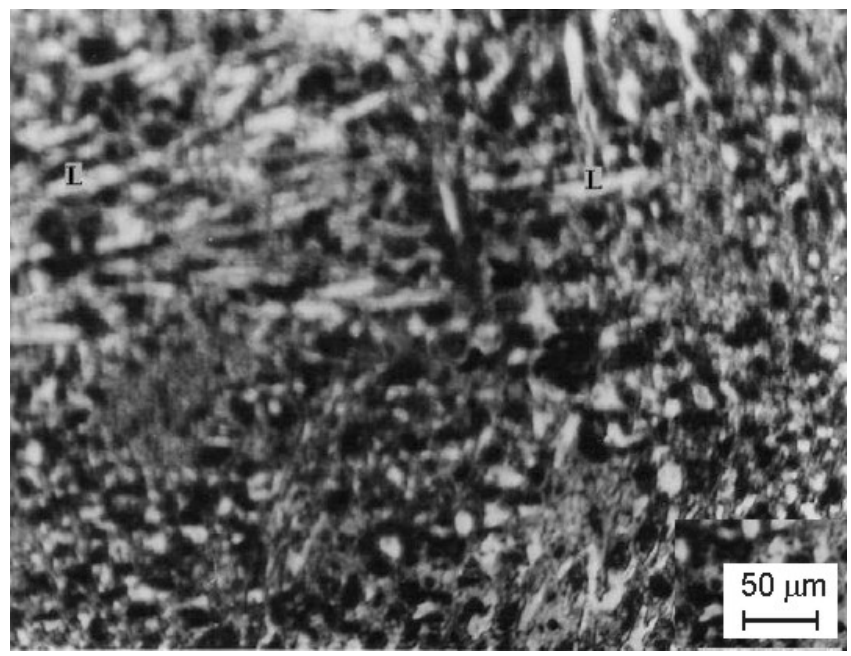

Figure 8. Optical photomicrograph of HT metal cast $10 \%$ manganese bearing sample (200X) 
compared to $10 \mathrm{M} 24$. The investigation carried out by Nishigaki (2004) on high functional material having vanadium carbide in it showed higher wear resistance due to the spheroidization and uniform dispersion of carbides in the matrix compared to either martensitic or austenitic high chromium iron. In the present case also, because of the presence of spheroidized carbides, the slurry erosion loss is lower in 5M24 compared to 10M24, thus indicating that the present work is in line with the reported work (Nishigaki 2004).

Another work (Jiang et al 2006) on the corrosionerosion studies on high chromium iron system containing $28 \% \mathrm{Cr}$ revealed significant improvement (almost two times) in these properties following heat treatment compared to $15 \%$ chromium iron. The reason has been attributed to the presence of fine carbide size and its uniform distribution in the matrix. Therefore, the present finding of superior slurry wear characteristics in 5M24 compared

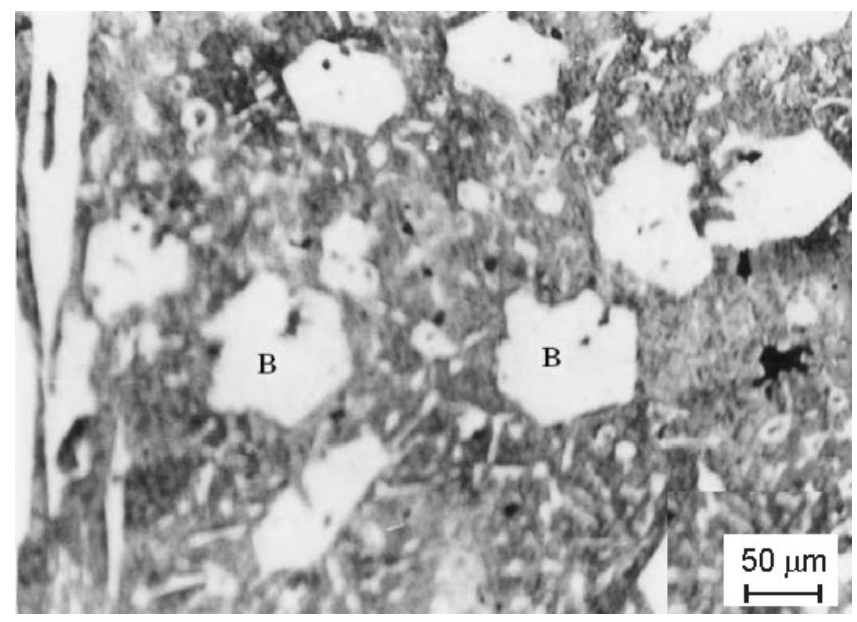

Figure 9. Optical photomicrograph of HT sand cast 5\% manganese bearing sample (200X).

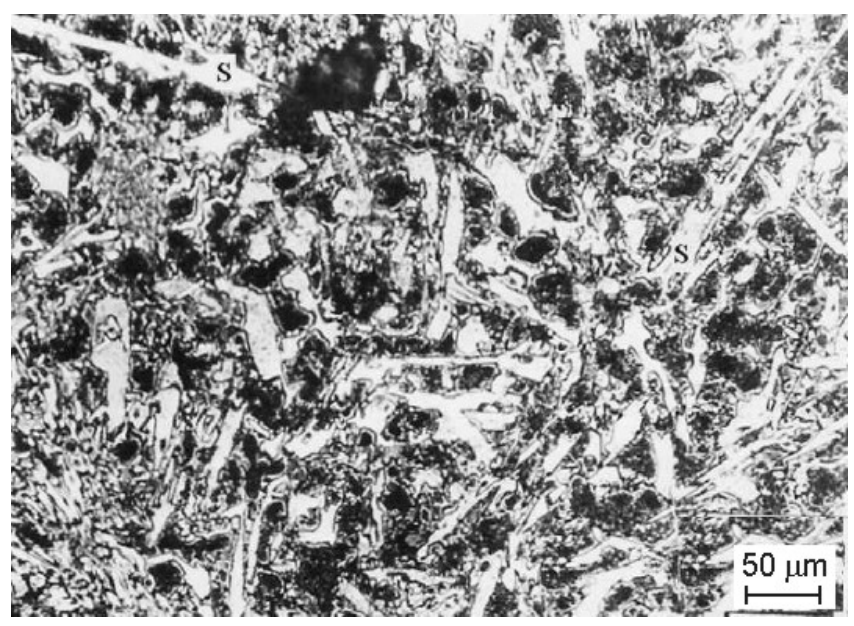

Figure 10. Optical photomicrograph of HT sand cast 10\% manganese bearing sample (200X). to $10 \mathrm{M} 24$ following heat treatment is in agreement with the reported (Jiang et al 2006) data.

The key point that emerges from this part of the work is that irrespective of the manganese levels adopted (i.e. 5 or $10 \%$ ), the metal mould samples, expectedly, show primary carbides of much smaller size compared to the ones seen in sand mould sample, owing to the differences in the cooling rate characteristics.

The differences observed in the microstructure are traced to the variations in heat conduction in the metal and sand moulds, the former facilitating higher heat transfer. The work records that the small-sized carbides occur in faster cooling rate conditions. This agrees well with the recorded features reported in the literature (Seetharam et al 1995), wherein greater time available for diffusion and attendant enlarged size of carbides are reported for sand moulds. Further, it is interesting to note that an investigation (Norman et al 1977) relating to the cooling rate

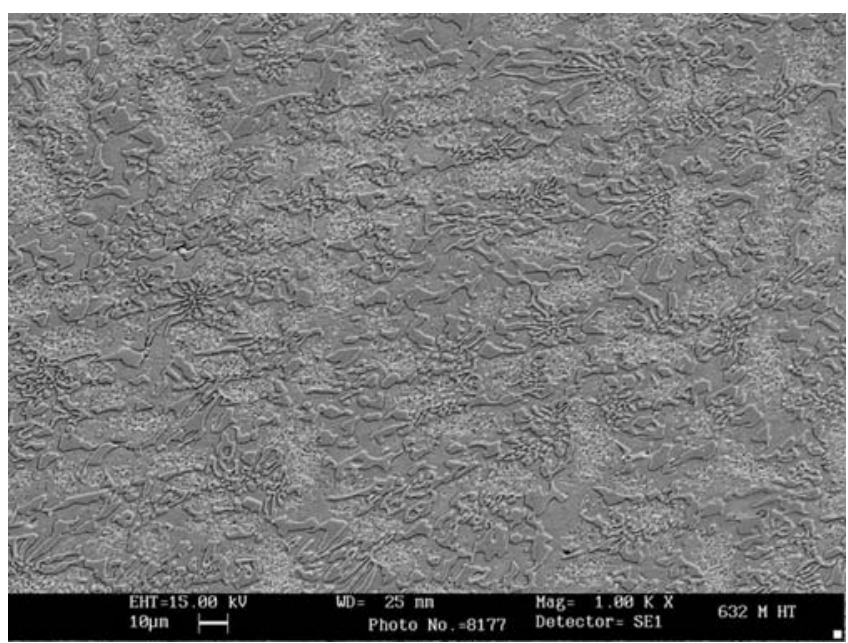

Figure 11. SEM picture of metal mould HT 5\% manganese bearing sample (1000X).

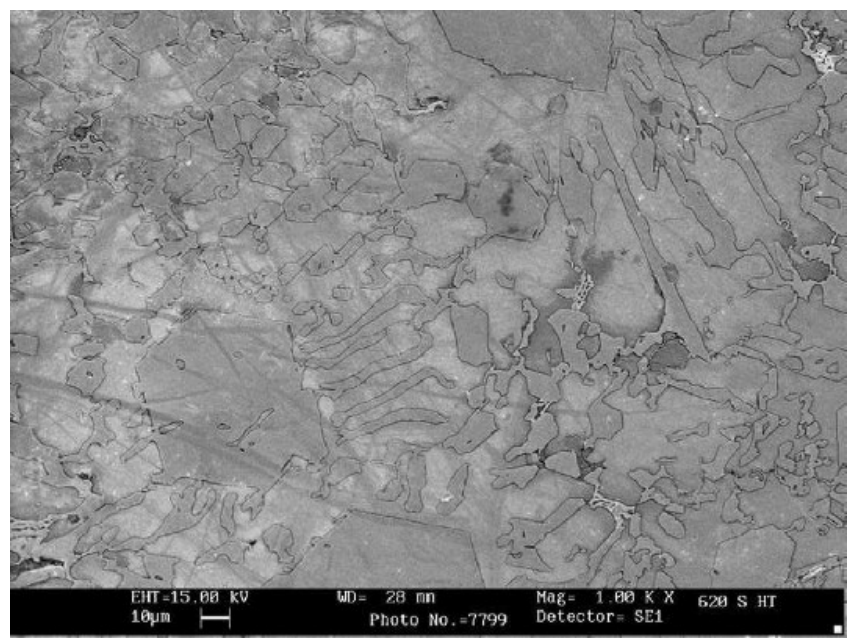

Figure 12. SEM picture of sand mould HT 5\% manganese bearing sample (1000X). 
effect on the mechanical properties reports that higher the rate, finer is the chromium carbides on the surface of casting. The present finding of finer carbides obtained in metal moulds is in line with the earlier work (Norman et al 1977). In another investigation (Junyi and Yuding 1987), unidirectional solidification (achieved by adopting a chilling arrangement on one side of the casting), was employed in a similar alloy system wherein fine carbide formation, very close to the chilled zone as well as on the chilled surface, was observed.

Thus, the major difference seen for sand cast samples (5S24 and 10S24) is higher austenite retention and lower hardness compared to the corresponding metal mould cast samples (i.e. 5M24 and 10M24) both in the as-cast and heat-treated conditions. The reasons for lowering of the hardness are attributed first to the carbide morphological features such as size, its distribution and volume fraction and then to the increased austenite content. These features are supportive of slurry erosion data trend obtained for these two cases (compare figure 3 with figure 2). Kim et al (2006) investigated the effects of heat treatment on the wear resistance and fracture toughness in duo-cast materials, viz. high chromium white cast iron and low chromium steel materials. The heat treatment led to the improvement in the wear behaviour due to the considerable reduction in selective wear of the matrix and spalling tendency of carbides. In the present case too, the slurry wear characteristics have improved due to the carbide morphological features as well as matrix transformation on account of heat treatment. Further, it is well known from the published literature (Laird 1993; Tabrett et al 1996) that when the grain/carbide size increases beyond a certain level, both the strength and hardness show a declining trend. Thus, the present finding of lower hardness and hence a higher slurry erosion loss in 10M24 and 10S24 (due to the carbide size being bigger) in these cases compared to their 5\% manganese bearing counterparts is in agreement with these published data (Laird 1993; Tabrett et al 1996).

In summary, the work emphasizes first the role played by the type of mould and hence the cooling rate and then on how the subsequent heat treatment (i.e. spheroidization of carbides) brings about a performance difference in respect of the wear properties of $\mathrm{Cr}-\mathrm{Mn}$ alloy systems. That the structure property correlation route can effectively be adopted for this system too, has unambiguously been illustrated in this work.

\section{Conclusions}

The following salient points emerge from the above study. (I) Compared to the higher Mn bearing system, the lower i.e., $5 \%$ manganese bearing sample, shows superior slurry erosion property irrespective of the mould variety used.
(II) Metal mould samples display higher slurry erosion resistance compared to sand cast variety.

(III) The spheroidization tendency of carbides following heat treatment has a marked influence in respect of the slurry erosion behaviour of metal cast samples compared to the sand moulded ones.

\section{Acknowledgements}

The authors wish to thank Mr S Vynatheya and Mr J Shankar, MTD, CPRI, Bangalore, for the assistance rendered in conducting the experiments. One of the authors (Kishore) would like to thank CSIR for the award of a fellowship under E. S. Scheme.

\section{References}

Annual Book of ASTM Standards 1984 G65-94, Section 3, 0302 ASTM, Philadelphia, 239

Basak A, Pening J and Dellewyns J 1981 AFS Int. Cast Metal J. 12

Gundlach R B 1988 High alloy white irons, ASM metals handbook, castings (Metals Park, Ohio: ASM International) 15 p. 678

Gundlach Richard B and Doane Douglas V 1997 Alloy cast irons, ASM metals handbook, 1 (Materials Park, Ohio: ASM International) p. 85

Hebbar B M and Seshan S 1989 Wear resistant casting for thermal power plants, National workshop on wear and erosion of materials in thermal power stations (Bangalore: CPRI) 3A1

Jiang Ye-hua, Li Zu-Lai, Qi Ting and Zhou Rong 2006 Zhuzao Jishu Foundry Technol. 27333

Junyi S and Yuding J 1987 International conference on wear of materials (New York: ASME) p. 661

Kim Chang Kyu, Lee Sunghak and Jung Jae-Young 2006 Metall. \& Mater. Trans. A37 633

Laird II G 1993 AFS Trans. 128487

Maratray F 1981 AFS Int. Cast Metal J. 55

Nishigaki K 2004 Eng. Mater. 5291

Nong Wan, Dong Jian-Xin and Xie Xi-Shan 2005 Zhuzao Jishu, Foundry Technol. 26723

Norman T E, Solomon A and Doane D V 1977 AFS Trans. 77 242

Oh Hongsug, Lee Sunghak, Jung Jaeyoung and Ahn Sangho 2001 Metall. \& Mater. Trans. A32 515

Patwardhan A K, Mehta M L and Sharma C P 1981 AFS Int. Cast Metal J. 3

Sampathkumaran P, Seetharamu S and Kishore 2005 Wear 259 70

Sapate S G and Rama Rao A V 2006 Tribology Int. 39206

Seetharamu S and Sampathkumaran P 1991 Wear and erosion of thermal power station components, CPRI Technical Report No. 219, Bangalore

Seetharamu S, Sampathkumaran P and Kumar R K 1995 Wear 267159

Tabrett C P, Sare I R and Ghomashchi M R 1996 Int. Mater. Rev. 4159

Tekeli Suleman, Gurall Ahmed and Guru Metin 2007 Mater. Sci. Forum 534-536 629 